\title{
"My kid, my rule": Governing children's digital footprints as a source of dialectical tensions between mothers and daughters-in-law
}

\author{
Davide Cino*, University of Milan-Bicocca, Department of Human Sciences for Education, Italy \\ Chiara Dalledonne Vandini, University of Bologna, Department of Education, Italy \\ ${ }^{*}$ Corresponding author: d.cino1@campus.unimib.it
}

\begin{abstract}
This paper reports on findings from an exploratory study on social media dilemmas (SMDs) mothers experience about their children's social media presence when their mothers-in-law share about their offspring online, violating their boundaries expectations. The work is theoretically informed by systems theory and communication privacy management theory. A parenting forum was researched to investigate how mothers themselves frame these dilemmatic situations through a thematic analysis of a sample of 1224 posts from 38 discussion threads focusing on these issues. This work shows the disorienting nature of SMDs leading mothers to seek support through online communication. Findings from this study further suggest that sharing about minors on social media can cause dialectical tensions between interacting systems (i.e. the nuclear and the extended family), with mothers claiming and expecting first-level agency in managing their children's digital footprints to foster systemic differentiation in the digital home.
\end{abstract}

\section{Keywords}

sharenting, social media, privacy boundaries, MIL-DIL dialectical tensions, digital parenting, grandsharenting, datafication of childhood

\section{Introduction}

In the contemporary digital age, social media use is embedded in family life in the global North (Lupton, Pedersen, \& Thomas, 2016). Through a circular process of media domestication by which family and the media shape each other (Silverstone, 2005), families incorporate social media sharing in their daily routines by posting representations of their members on the Web (Holloway \& Green, 2017). In this context, Sharenting, or the act of "sharing representations about one's parenting or children online" (Blum-Ross \& Livingstone, 2017, p. 110), has become a usual habit for families (Livingstone, BlumRoss, \& Zhang, 2018). A growing body of research on the topic has developed in the past few years, focusing mostly on mothers sharing photos of the offspring on social media (Kumar \& Schoenebeck, 2015). While the literature on the topic highlighted benefits associated with this practice in terms of increased sense of connectedness with important people in one's life (Bartholomew, Schoppe-Sullivan, Glassman, Kamp Dush, \& Sullivan, 2012), scholars have also considered the lack of children's agency in managing their digital footprints (Supple Bartels, 2015). In this sense, it has been stressed the role of parents as children's personal information gatekeepers (Steinberg, 2016) who play an agentive role in deciding about their offspring's online privacy. Ammari, Kumar, Lampe and Schoenebeck (2015) found that within the nuclear family, mothers do most of the online disclosure management work, by setting explicit and implicit rules for relatives and friends - especially grandparents - on whether and what to share online about their children, with the aim of defining boundaries between interacting systems. Thus, although Sharenting seems to be motivated by the desire to stay in touch with other family members, parents do care about being the ones in control of this practice. Such an endeavor is in line with communication privacy manage- 
ment theory (Petronio, 2002), according to which families erect metaphorical privacy boundaries to draw a line with the outside world. According to systems theory, then, different degrees of boundaries can result in different levels of systemic differentiations (Minuchin, 1974). When parents guard their children's online presence, privacy stewardship is enacted as the responsibility they "take on when deciding what is appropriate to share about their children online and ensuring that family and friends respect and maintain the integrity of those rules" (Kumar \& Schoenebeck, 2015, p. 1310). As children get in touch with other people from different systems who may have different photo-sharing preferences compared to the family (Autenrieth, 2018), such a negotiation becomes pivotal to guarantee parents an appropriate level of control. This may be the case of grandparents sharing about their grandchildren online without parents' consent, engaging in "grand-sharenting" (Damkjaer, 2018). The emotional valence of grandparents using social media to see photos of their grandchildren has been documented in the literature (Ivan \& Hebblethwaite, 2016). Little research, though, has investigated dilemmatic situations stemming from boundary crossing having to do with grandparents themselves sharing about grandchildren online.

In the realm of family dilemmas, research supports that violating boundaries is a main source of dialectical tensions between the nuclear and the extended family, especially with the in-laws (Danielsbacka, Tanskanen, \& Rotkirch 2017). In particular, it has been sustained that when it comes to poor boundary regulations, the most difficult in-law relationship is the one between daughters- and mothers-inlaw (henceforth DILs and MILs; see Fischer, 1983).

This paper builds on a broader project studying digital dilemmas parents experience concerning their children's digital footprints, focusing on the dialectical tensions experienced by DILs and MILs when the latter violates mothers' expectations about their offspring's online presence. To this end, a parenting forum was used as a site of research to investigate how parents themselves define and describe these dilemmatic situations, in their own words. A purposive sample of 38 discussion threads and 1224 comments, specifically focusing on tensions between DILs and MILs concerning children's social media presence, was thematically analyzed. The original contribution of this work rests on its understanding social media quandaries as a potential source of family communication issues to be considered by communication, child and family studies scholars when investigating contemporary families and their systemic relationships.

\section{Literature review}

This section reports on relevant literature to frame our work. First, a review of studies on the governance of children's social media presence is provided. Following, pertinent frameworks concerning systems theory (Minuchin, 1974) and communication privacy management theory (Petronio, 2002) will be briefly explained. Finally, the rationale behind our choice to focus on dialectical tensions between DILs and MILs will be supported reporting on related empirical studies.

\subsection{Managing children's social media presence: A matter of agency}

Children's social media presence starts well before they are born, with ultrasound sharing marking the first step in the construction of a child's online identity (Leaver, 2018). Bartholomew et. al (2012) found that $79 \%$ of new mothers and $76 \%$ of new fathers had uploaded photos of the offspring on Facebook in the U.S., mostly on a monthly basis. A large-scale quantitative study in the U.K. found that three in four parents who access the internet monthly share photos or videos of their children, with little gender differences (Livingstone et al., 2018). According to the same study, parents' photo-sharing frequency about the offspring with close family and friends has an inverse relationship with the child's age, reaching a peak with children under four. Sharing tend to decrease as a 
child grows into adolescence, possibly as a request from the child himself / herself (Livingstone et al., 2018). In this regard, scholars have argued that early childhood, in particular, is a critical site of datafication for children (Mascheroni, 2018a), which is "the ability to transform almost every aspect of social life into online data" (Mascheroni, 2018b, p. 517). Taken together, these data support that sharing pictures of children on social media is a common habit for parents today in the global North. Sharenting, however, comes less light-heartedly than what it seems, as parents reported grappling with digital dilemmas concerning their children's privacy online (Chalklen \& Anderson, 2017). This suggests that mothers and fathers are not naïve about their children's online presence, which in turn becomes an issue to deal with in the digital home, where sometimes "anti-sharenting" positions are taken (Autenrieth, 2018). Ammari et al. (2015) found that, while both fathers and mothers are involved in curating their children's online presence, mothers take the lead "in doing the work of posting content online, as well as managing disclosure about their children" (p. 1902), which also involves setting boundaries with third parties in the form of photo-sharing rules. The authors conceptualize this responsibility as a new gendered domestic labor for mothers. In this case, managing boundaries means assuring parents' agentive role.

Agency has been conceptualized in terms of "people's beliefs about their capabilities to exercise control over events that affect their lives" (Bandura, 1989, p. 1175). This concept is particularly appropriate here, as adults sharing representations of children online who are too young to consent themselves do, de facto, act as children's proxy even when they have not a say in, nor sometimes an understanding of the process. While many actors can record details of children online (Lupton \& Williamson, 2017), parents play, to different extents, the dual role of not only narrators of their children's lives, but also personal information gatekeepers (Steinberg, 2016). As Leaver states, when posting online "the shared presumption [...] is that the agency of the user is central. There is a presumption that identity should be controlled, curated and managed by the self in question" (Leaver, 2015, p. 151). As the boundaries between the parents' and the child's self can blur when sharing about the offspring (Blum-Ross \& Livingstone, 2017), parents end up becoming agents of their children's social media presence. Thus, up to the point where children's themselves can start to express their opinions about Sharenting (Ouvrein \& Verswijvel, 2019), it's parents who control the child' self and its extension online.

Governing the child's relationship with media, however, is not new. In turn, the idea of a "good enough parent" who pays attention to the child's experience of media and technology in the household continues to function as a cultural model, defining specific parenting roles and moral identities (Caronia, 2010). The history of parents' concerns over the use of new technology and media is a long one in family life (Wartella \& Jennings, 2001). As technology and media are rooted in the lives of contemporary families (Wartella, Rideout, Lauricella, \& Connell, 2014) the expectations for parents to be involved in their children's media consumption continue to be high (Blum-Ross \& Livingstone, 2016). Such an effort, we argue, can be understood within the intensive parenting ideology (Shirani, Henwood, \& Coltart, 2012), a Western childrearing philosophy holding parents - especially mothers (Hays, 1998) - accountable for their children's lives, including their relationship with technology.

In the realm of social media, all of this translates in new efforts parents are expected to make to protect their children's data and privacy online (Livingstone, Stoilova, \& Nandagiri, 2018). Having adults as third-parties sharing about children online, though, represents a peculiar case per se. When it is other people who share about children, their online presence becomes passive, calling for the responsibility of the adults who are doing the sharing to manage possible risks and safeguard their privacy online. Not only, though, is the current generation of parents probably 
the last one who stepped into the online realm autonomously (Autenrieth, 2018), but this also means that when it comes to children's social media presence contemporary parents cannot rely on their own experiences with traditional media, nor on their own parents' knowledge (Leaver, 2015). In turn, new cultural models (Holland \& Quinn, 1987) are currently in the making, stemming from dilemmatic experiences where parents do, indeed, question their online sharing habits (BlumRoss \& Livingstone, 2017). As an example of that is the privacy/openness paradox, where mothers who share about their children on Facebook are happy to do so, but also worried as they recognize potential hazards caused by their sharing behavior and tend to rely on a risk-benefit ratio evaluation to regulate their photo-sharing experience (Chalklen \& Anderson, 2017). However, this assessment still implies the agency of the parent in deciding what kind of behavior can be considered acceptable or not online. It follows from here that other sources of dilemmas can generate from members of systems external to the nuclear family, like grandparents, posting about grandchildren online. Even if well intentioned, occurrences like this can collide with parents' expectations about social media privacy, causing boundary violations and asking for reparative courses of action to be taken.

\subsection{Managing family's privacy boun- daries: Lessons from systems theory and communication privacy management theory}

According to Webb and colleagues (2015) a peculiar characteristic of social media is that they afford boundary crossing in their own design for the opportunity offered to users to share contents not only about themselves but also others. In the realm of family relations, new media contributes to "a redefinition of rules in relationships, particularly with whom we share particular information and manage emerging boundary issues" (Hertlein, 2012, p. 377). When using social media, families try to preserve clear boundaries between themselves and the world outside, conversa- tionally setting rules about what to share online and who can access their accounts (Sharaievska \& Stodolska, 2015). When it is other people who share contents about their children online without consent, most parents get frustrated because of this boundary crossing (Smith, 2014).

The extended family - including both the family of origins and in-laws - represents an important system connected to the nuclear family (Fingerman \& Hay, 2002). At the same time, building on the concept of family boundaries ambiguity (Boss \& Greenberg, 1984) - or a state of non-clarity about who belongs to the family system - the extended family has been considered part of an external system due to different patterns of interaction between members (Sharaievska \& Stodolska, 2015). On this basis, while we do recognize the extended family - specifically here, the mother-in-law of the child's mother - as being part of a circle close to the nuclear family, we refer in this study to the figure of the MIL as a member of a system that, although expected to be part of a child's life, is external to the nuclear family.

Systems theory (Minuchin, 1974) posits that clear boundaries function as rules aimed at fostering a neat systemic differentiation by defining who, and to what extent, participates in a system. Diffuse boundaries, in turn, can cause a situation of enmeshment where systems tend to tangle up and the different needs and values of different members are difficult to distinguish (e.g. online privacy orientations). When it comes to making decisions about children's social media presence, parents may want to be the ones setting rules for members of other systems surrounding the child to respect (Ammari et al., 2015), marking clear boundaries that, if crossed, could cause systemic enmeshment and relational tensions. This could be the case when a MIL shares about one's grandchild online without parents' consent.

Communication privacy management theory (CPM; Petronio, 2002) provides a good framework to further conceptualize boundary violations when it comes to social media privacy. To this respect, three main CPM's tenets well explain the way 
people manage boundaries of personal information between interacting systems. Privacy ownership, according to which people believe they own their personal information and think they are the ones who can decide to grant access to selected "co-owners". Privacy control, which further indicates that even when granting access to third parties, people still feel they are the ones regulating their privacy. Finally, when boundary conflicts take place - intended as situations where there is a discrepant coordination of privacy ideals between parties - privacy turbulence occurs, where people feel co-owners have violated their boundary expectations. Turbulence, in turn, calls for solutions to be taken on the part of the owner to claim first-level ownership, leading either to relational damage or improvement (Steuber \& McLaren, 2015).

Several studies have used CPM stressing the fuzzy dimension of online privacy as known and unknown users may have access to the posted contents (Child \& Starcher, 2016). For the purpose of this study we will focus on circumstances where third-parties share about other people's children online, making privacy decisions that collide with their own agency causing privacy ownership violations (Degroot \& Vik, 2017). We interpret these predicaments as an extension of family privacy dilemmas which "call into question the way boundaries are usually regulated both within the family and to outsiders", asking families "to cope with situations where there may be too much permeability" (Petronio, Jones, \& Morr, 2003, pp. 24, 29) and systems can get enmeshed in terms of privacy values and expectations. The next section will look at how such a state of boundary entanglement can occur within the MIL-DIL systemic relationship.

\subsection{The specificity of dialectical tensions between mothers- and daughters-in- law}

The focus of this paper on the relationship between DILs and MILs is motivated by the fact that it can be one of the most problematic in family life. According to Rittenour (2012) this is evident not only in the more diffused Gerede (i.e. "idle talk", Heidegger, 1996) as narrated in cultural and media representations, but also in empirical literature. Studies support that the likelihood for dialectical tensions over boundary issues are higher with parentsin-law than parents of origins, especially between DILs and MILs (Danielsbacka et al., 2017). Scholars claim that this may be due to different family cultures / history and because of MILs' higher involvement than other in-laws with their sons' families (Fingerman \& Hay, 2002). According to the triangular theory of in-law relationships (Duck \& Kirkpatrick, 2006), these connections are characterized by the presence of a linchpin (i.e. the family member creating the in-law relationship), the spouse of the linchpin (e.g. the DIL), and the relative of the linchpin (e.g. the MIL). The in-law relationship is probably the weakest link of the triad due to its involuntary nature (Morr Serewicz, 2008). Several factors have been linked to relational issues between DILs and MILs, such as an intrusive behavior of MILs in DILs' family life and their criticizing DILs' childrearing practices, which can result in more boundary violations (Fischer, 1983). Issues managing intergroup boundaries are at the heart of inlaw relationships (Rittenour \& Soliz, 2009), with implications on marital satisfaction concerning the way these matters are addressed (Bryant, Conger, \& Meehan, 2001). In fact, agreement between DILs and husbands in managing boundaries with the MIL is linked to successful relationships, while having the husband siding with the MIL or not taking a position can cause tension (Rittenour \& Kellas, 2015).

Little is known, though, about predicaments stemming from cases of boundary violations due to MILs posting about grandchildren online, nor how they can impact the relationships between parents as members of the nuclear family supposed to cohesively set boundaries with interacting systems. Also, mothers play the role of gatekeepers in regulating not only their children's social media presence (Ammari et al., 2015) but also the relationship of the child with extended family / inlaws (Fagan \& Barnett, 2003). As such, this 
contribution looks at the dialectical tensions experienced by DILs and MILs when the latter violates mothers' boundaries of their offspring's online presence, and how these dilemmas impact family relationships.

\section{Studying social media dilemmas online}

The broader ongoing project this paper is part of explores social media dilemmas (SMDs) parents experience about their children's social media presence and privacy (Blum-Ross \& Livingstone, 2007; Chalklen \& Anderson, 2017). As Petronio et al. (2003) claim, the peculiarity of dilemmas is that, unlike issues, they do not rely on a binary choice between right and wrong, but reflect "situations in which there are conflicts between multiple values and interests, in which actors are uncertain about appropriate courses of action to take" (Petronio et al., 2003, p. 29). A specific characteristic of SMDs associated with children's online presence is that they are brand new, thus parents may find themselves disoriented when dealing with them and look for advice.

In today's family life the Web plays an important role to support parents in the global North - especially mothers - via online communities of advice (Lupton et al., 2016). Advice, "by its very nature, responds to some kind of dilemma" (Blum-Ross \& Livingstone, 2016, p. 12). In this regard, scholars have been studying parenting forums as sites where parents can find / provide social and emotional support, normalize their experience and address questions they would not address elsewhere thanks to an environment affording anonymity (Brady \& Guerin, 2010). This is in line with the hyper-personal model of interpersonal communication (Walther, 1996, 2007), according to which Computer Mediated Communication may allow people to engage in more meaningful interactions than those occurring Face to Face.

Data for this project were collected from the United States-based BabyCenter community, as one of the most popular parenting forum online (Lupton et al., 2016). According to the website information page, it reaches over 50 million parents all over the world, with seven in ten new and expectant mothers using it monthly in the United States. ${ }^{1}$ A content analysis of the website (Jang \& Dworkin, 2012) found that most members are mothers of 20-30 years of age, and that conversations concern areas such as pregnancy and labor, issues related to the baby, and personal and common problems concerning parenting challenges.

The choice of using a parenting forum as a site of research was motivated by three main assumptions. First, the literature supports that these platforms can be good sources of data collection with respect to several topics, like pregnancy (Cappellini \& Yen, 2016), birth (Das, 2017), or health choices (Hookway, Elmer, \& Frandsen, 2017). Second, online discussion sites have been shown to generate good quality natural data (Smith, Bulbul, \& Jones, 2017). Third, they build on other users' responsiveness to engender rich discussions (Holtz, Kronberger, \& Wagner, 2012). Given the exploratory nature of this study, this approach was considered appropriate, as it allowed us to investigate dilemmas that parents deemed disorienting (see Mezirow, 1991) in terms of possible courses of action, and thus worth discussing. Also, by studying natural data on a parenting forum we were able to see how SMDs are experienced, understood, and co-constructed not only by the original posters, but also recipients taking part in the conversation.

In an age where social media and digital technology are embedded in family life, scholars have called for more evidence to explore "how boundaries around technology are formed, maintained, and adjusted" (Sun \& McMillan, 2018, p. 182). The present contribution seeks to investigate how boundaries of children's social media presence are understood and experienced within interacting systems, with regard to the relationship between MILs and DILs.

1 Available at: https://www.babycenter.com/ about. 
As such, this study is guided by the following exploratory research questions:

, RQ1: How do mothers frame dilemmas with MILs concerning their children's social media presence?

, RQ2: What solutions to these dilemmas are discursively proposed and co-constructed?

, RQ3: What impact can SMDs have on family systemic relationships, with particular regard to the DIL-MIL-Husband triad?

\subsection{Data sampling and analysis}

Data for this project were collected from the BabyCenter-Community forum, a public area of the website. Being our focus on mothers talking about posting photos or information of children on social media, the forum was searched for instances of threads related to our topic of inquiry using a string of keyword search terms. A sequentially top-down data collection method followed (Eriksson \& Salzmann-Erikson, 2013), where the first 150 pages of results were screened for considerations (1500 threads). Thus, we filtered all the discussions to select those in line with our study, dealing with sharing about children on social media. We found many threads dealing with questions about sharing not only pictures of children themselves, but also sonograms, status updates on pregnancy, labor, etc. Because these types of postings constitute the online "social worlds of the unborn" marking the beginning of his / her online presence (Lupton, 2013), we decided to include them in our sample, expanding our focus toward a holistic investigation of children's social media presence as it evolves over time. The final broader sample of threads concerned either mothers' own sharing behavior or other people sharing about the original poster's child (e.g. grandparents, relatives, etc.). The latter is the focus of this contribution. For the purpose of this paper, a purposive sub-sample of threads was selected from the main sample (Palys, 2008), concerning cases of boundary predicaments where the original poster (i.e. the DIL) would complain about MIL posting pictures / information of her born / unborn child / children on social media. Although several threads concerned even other in-laws and members of the extended family sharing about the child, informed by the literature on MILDIL's dialectical tensions (Rittenour, 2012) and consistently with this paper's research questions, we narrowed our focus to discussions exclusively focusing on MILs. This led to a final sub-sample of 38 threads and a total of 1224 comments, posted between 2014 and 2018. The number of comments per thread ranged from 5 to $95(M=32.21$; $S D=21.98$ ). Mothers dealt with these dilemmas either during pregnancy or after the child was born. When children's age was reported, this was in the early childhood stage. All the posters self-identified as women either with usernames or in the comments.

In line with perspectivism (Cornish, Gillespie, \& Zittoun, 2013) we tried to bring a diversity of outlooks to the analysis by iteratively coding the data with the help of a research assistant. Also, we have tried to constructively discuss our interpretative biases, while seeking to embrace a "hermeneutic of suspicion" (Ricoeur, 1970). Given the exploratory nature of this study, we opted for an inductive coding approach to investigate common themes among discussion threads and comments (Boyatzis, 1998). The units of analysis were the single posts within the threads, while keeping track of their conversational evolution. First, the principal investigator and the research assistant read through threads independently applying initial codes to the data (Saldaña, 2009). The resulting list of codes was revised comparing same units of analysis to look for correspondences and resolve discrepancies (Campbell, Quincy, Osserman, \& Pedersen, 2013). Following, the initial codes were organized into a smaller, patterned number of categories (Miles \& Huberman, 1994). The developing codebook (containing definitions, examples, and instructions) was iteratively discussed to resolve disagreements. The codebook was then tested by the second author, first independently writing analytic memos, then further revising it with the 
first author. Finally, the first and second authors completed a third pass to review all the threads and make adjustments to the codebook as needed. While our analysis was exploratory in nature, inductive findings were further conceptualized, developed and organized with respect to our theoretical frameworks.

In analyzing these interactions, we looked at how actors-in-conversation framed both the stories being told and discussed and the characters of these stories (i.e. mothers themselves, other actors involved in the stories like children, partners, relatives, etc.). According to Goffman (1974) frames are schemata of interpretation helping people understand, organize, and give meaning to experiences. Frames are not given once and for all but are, in turn, re-organized and re-constructed through social interaction (Bercelli, 1999). Online interpersonal communication fosters the production of mediated frameworks of reference (Das, 2017) as lenses through which looking at and (re)interpreting the social world and one's personal life. Through the mesolevel of interaction (see Formenti, 2012) taking place on parenting forums, people can communally make sense of and interpret their experiences, while constructing and attaching meaning to them. In this sense, this work looks at the discursive products of online conversations between parents as a form of social construction where not only dilemmatic events are discussed, but the social and moral identities of the "characters" of these events are also constructed (Orletti, 2000).

In reporting our findings we recognize that being this an exploratory study where researchers worked with a non-probabilistic sample of natural data and had no involvement in their production, and given the anonymous nature of these interactions not allowing to get more contextual information about these posters than those already shared, our approach was limited. These limitations can be tackled by adopting different methodologies in future research, as will be discussed in the conclusions. Also, in interpreting these results it is important to recognize the female-dominated nature of parenting forums (Dworkin, Connell, \& Doty, 2013) and the gendered dimension of these interactions.

\subsection{Ethical considerations}

Online data collection rises ethical concerns. Many scholars who employed similar approaches did not seek consent when data were publicly available, not protected by password / forum registration, and posters used usernames, as reported in the debate about ethical use of online data (Roberts, 2015). In their guidelines on analyzing Internet Forums, Holtz and colleagues refer to open forums claiming that "usually, the postings in these forums can be read by everybody. In our view, this justifies the consideration of communication within such forums as "public behavior" (2012, p. 57). Further evaluating privacy concerns, though, was pivotal to us.

The legitimacy for researchers to collect public data on online forums, in fact, has been questioned since the very beginning of the World Wide Web. King (1996) stressed the importance of reflecting on the ethics of online research thoroughly in order to do no harm to posters, problematizing the opportunity for researchers to just collect and analyze data without giving ethics some serious thoughts. In an effort to offer scholars in the late 1990s guidelines to orient themselves, the author focused on two broad dimensions to take into account when evaluating whether and how collecting data online: group accessibility and perceived privacy. According to the author, researchers need to evaluate whether the group is accessible (e.g. with no registration) and to what extent posters perceive their conversations as private (possibly by asking them directly). Such an approach was later supported by Marx (1998) who stressed the need for informed consent when using natural online data. In his "netnography" framework for online research, Kozinets (2002) claims that researchers should always disclose their presence when studying online interactions. While such a framework can certainly be appropriate when studying private online communication (where one 
can assume there is a high expectation of privacy), some scholars state it is too strict if applied to public communication as well. As an example, Sugiura, Wiles, and Pope (2017) report on their experience where trying to contact posters to ask for consent was extremely challenging, leading them to claim that "the convention that all research participants should give full and free consent to participating in research is, in the online context, neither possible nor necessary" (p. 195). People conversating online have been reported to react badly when researchers disclosed their presence, as it was the case for Hudson and Bruckman (2004) in their observation of chatroom conversations. It is however important to stress that archived asynchronous conversation on public forums and synchronous interaction in a chatroom cannot be easily compared: according to the AoIR (2002), the former is more public than the latter. When working with archived and no longer active conversations as we did, we argue, researchers are not really taking part in the interaction, nor really "lurking" or acting in disguise, as the conversation has in fact already taken place in a moment in time that does not coincide with the one when data are being collected and analyzed (like it may very well be the case when recording live chatrooms).

The debate on ethical use of online data is currently open and no agreement has been reached. As such, researchers may face dilemmas in deciding whether and how - if at all - treating such data. A choice needed to be made on our part as well.

According to the Association of Internet Researchers scholars should make situational decisions and not along binary lines (Markham \& Buchanan, 2012). As such, we thoroughly looked at published scholarship focusing on the same or similar forums. While studying the BabyCenter forum following the steps listed in Brady and Guerin (2010) and Reid (1996), Jang and Dworkin (2012) did not seek consent. Neither did Milne, Weijs, Haines-Saah and McLaren (2017), Pedersen and Smithson (2013), Pedersen and Lupton (2018), Das (2017), Whiteman (2012), Appleton,
Hons, Fowler, Brown and Hons (2014), or Hine (2014). Informed by these scholars and the abovementioned guidelines, we only studied already existing discussions, publicly accessible (i.e. no needing registration / password / authorization to be retrieved), asynchronous, and archived as no longer active at the time of collection. As other researchers make the case for (see Das, 2017; Whiteman, 2012) this made getting in touch with posters virtually impracticable.

Evaluating posters' perceived privacy was challenging. While, on the one hand, Eysenbach and Till (2001) argue that posting publicly doesn't necessarily mean that posters are consenting to their statements being collected, on the other, when focusing on public communication occurring in public areas of a forum "the multiparty and anonymous nature of Internet forums means that contributors can expect their posts to be read by strangers. In fact [...] when reading Internet posts, it becomes clear that contributors orient toward addressing a group of strangers" (Jowett, 2015 , p. 289). As such, we decided to collect and analyze these data, checking all the excerpts we used on the Google search engine to control their traceability as a further step to safeguard anonymity (Smedley \& Coulson, 2018).

\section{Findings and discussions}

In order to address our research questions, we organize our findings as follow: first, we describe what type of SMDs mothers experience and how they feel about it. Then, we describe how posters conceptualize the roles of: the MIL as the subject of the in-laws triad causing the boundary crossing and dialectical tensions; the mother as the one looking for a solution to get back control and protect her child's online presence; the husband as a third party whose behavior can foster or hinder systemic differentiation and define or not the nuclear family as a higher level system when it comes to choosing about children's social media presence. 


\section{1 "How on earth does one manage this?" - The disorienting nature of social media dilemmas}

The overarching characteristic of the opening posts in all the 38 threads was the presence of a SMD caused by a boundary crossing perpetuated by the MIL, which would cause the mother to lose agency in controlling the digital narrative about her child online. We classified these violations as either pre- or post-birth. Pre-birth violations $(\mathrm{n}=16)$ encompass occurrences where MILs shared about the unborn, by disclosing information concerning either the pregnancy status of the mother, gender reveal, and / or the labor. This pregnant mother's narrative is an example of that:

I'm due April 22, and in the past 24 hours, MIL has posted four different statuses or comments referring to the fact that she has 'less than 22 days' to meet her grandson. This irritates me to no end because I've told her so many times that the 22 is my due date and going over is not just a possibility, but very likely. [...] She doesn't listen and continues posting about meeting him in less than 22 days.

Post-birth violations $(\mathrm{n}=22)$, in turn, involve sharing pictures of grandchildren online after they are born and during their daily life, which were either sent to the MILs by parents privately, captured with a screenshot from parents' social media, or snapped by MILs themselves. As these mothers state:

My MIL is obsessed with Facebook. When she was here for a week after he was born she took a million pictures and posted ALL of them.

My MIL's pic is currently a picture of my daughter that has never been on social media. It is one of her monthly milestone photos sent to family because they asked. I just find it weird and it bugs me because it is not something I have posted.

In line with CPM (Petronio, 2002) either parents established boundaries preventively by setting explicit rules, or they relied on implicit rules thinking that knowing not to post about other people's children "should be common knowledge to everyone regarding kid photos." Consistent with previous studies, such occurrences show that sometimes people lean on a dimension of common sense when not stating clear privacy boundaries with family and friends (Steuber \& McLaren, 2015). Additionally, both pre- and post-birth violations were in the forms of what Degroot and Vik (2017) defined as pre-emptive disclosure violations - where MILs shared something mothers would have posted later - or discrepancy breaches of privacy where contents that were not supposed to end up online were shared.

Associated with these types of violations are the respective dilemmas stemming from mothers not knowing how to address these predicaments. This was evident in their words indicating doubts on appropriate steps to take, as these posters stressed:

\footnotetext{
I wanted to pick others' brains and see if I'm just overreacting and should just grin and bear it or if it's something that needs another conversation.
}

I keep questioning what the right course of action is.

In this regard, several mothers stressed how "Social media is a blessing and a curse" because of a set of new potential issues parents are not properly equipped to face. As this poster states, "the world is so different from when I was a kid, it's hard to know what the new norm is and what is safe," stressing the brand-new peculiar dimension of SMDs for contemporary families.

\section{2 "Why is it always MILs?" - Construc- ting the "boundary stomper"}

Both original posters and commenters identified the MIL as the source of the turbulence (Petronio, 2002) causing the dilemma. One peculiar characteristic across posts was a differentiation between the 
members of the family of origin and the MIL, as these excerpts exemplify:

As soon as my MIL gets a photo of her grandchildren she posts it on Facebook and I just feel offended that she didn't give us a chance to post our own child. My own mom is the complete opposite she hates nosy people so she won't post anything for a while herself.

My parents also ask us to send them photos we would be comfortable being included [on online photo-albums] vs. MIL who just does whatever she wants.

Marking this difference discursively framed the MIL as a "boundary stomper", whose nature was recurrently reinforced by other posters taking part in the conversation to stress this commonality of experience. As these mothers state:

Is your Mil my Mil?? I literally had this same exact issue with mine. She was always sharing my posts, and even started tagging herself in pictures of my son.

[...] do we have the same mother in law?

Consistently with the literature on dialectical tensions between DILs and MILs, posters tried to make sense of the boundary crossing by relying on a set of attributions that would explain MIL's behavior (Rittenour \& Kellas, 2015). We found that MILs' social media conduct was framed as either naïve, malicious, or pathological, following a differential degree of problematization.

The less problematic figure was the naïve Mil. These occurrences show posters making sense of the boundary crossing referring to affective reasons and lack of digital skills. Despite being bothered, DILs would explain MIL's posting behavior as motivated by a desire to show her excitement for the grandchild, without though being able to recognize/ understand potential harms or parents' desire of agency. As these posters stressed:
She's thrilled, and maybe she doesn't realize how upset you are. Does she know how to use privacy settings? [...] go easy when you talk to her, but do clarify your concerns, she may not be aware!

She might not even get why you feel this way or the dangers of social media. Can't blame her if she doesn't know I guess.

A common idea was that such a naivety was due to generational reasons, like this DIL who describes her MIL as "an older over-sharer (i. e. not digital native who understands how the internet is forever and not the same as real life) who has no understanding of online safety." Such an idea recalls that older generations can actually experience more privacy predicaments due to less knowledge and skills (Child \& Petronio, 2011).

The malicious MIL was the most recurring frame and defines a figure who wittingly violates boundaries and whose behavior can be anticipated due to a commonality of traits and previous experiences of boundary stomping. She is described as someone who "has zero respect", "likes to test boundaries" and "wants to feel like she has power" even when it comes to children's social media presence, as an extension of other dialectical issues. The interactional patterns that discursively constructed this figure were marked by their strong realism: for their very nature, MILs are defined as figures who will cross (social media) boundaries. As an example of that, let us focus on a mother's pre-birth violation experience, whose MIL shared the baby's gender reveal on Facebook. The DIL is now afraid she is going to do the same with birth announcement, stealing her the opportunity to be the one to do it in her own terms (i.e. sharing the news only with close friends a couple of days after the birth to take time to bond with the child). As in other occurrences, posters anticipated MIL's behavior calling for specific courses of actions on the part of the DIL to tackle the issue: 
She WILL post on Facebook whether you want her to or not. As soon as she finds out it will be on Facebook. Talk to her now. She WILL steal your announcement. She WILL argue with you that it was her right as the grandmother to do so.

Saying that the MIL "WILL" post on Facebook deterministically typifies her behavior as something predictable, by using language as a means to discursively construct a problematic figure. Thus, the malicious MIL was framed as fully responsible for the boundary violations, with posters attributing this to selfish motivations that are linearly explained, in their words, by MIL's attitude to cross boundaries.

Finally, the pathological MIL was a borderline figure who - despite being rare - represents the most problematized one. She was defined as "crazy" and "in need of mental help" and emerged in discussions where MILs were framed as too involved in parents' family life. As this poster claims:

She's harvesting photos so she can feed her emotional dysfunction. This enmeshment and obsession is not normal or okay.

For example, after being asked to remove pictures of her granddaughter from Facebook, a MIL refused because sharing would cause her joy and such a behavior was framed by posters as deranged due to her inability to control herself:

She's basically saying that sharing your kid's photos is an addiction she can't control.

While these figures are socially and interactively constructed (and not necessarily describe the actual MIL behind posters' words), framing the MIL as a boundary stomper called for some tangible solutions for the DIL to take in order to tackle the dilemma and restore agency.

\subsection{Being a Good mother, safeguarding the Child: solutions to restore agency} According to Petronio (2002), when faced with privacy predicaments people react to get back control. Experiencing a SMD, though, entails that there are doubts on appropriate courses of action to take, which led these mothers to ask for advice on how to restore parental agency. A common premise throughout all of the threads was a superiority of the mother over the MIL justifying her desire to control, which was exemplified by the overly recurrent expression "Your kid, your rule". As this poster claims:

You're the mom, you get to say what about your child is shared on social media, nobody else!

Such a position was also supported by those who did not agree with mothers' apprehensions, as this poster stressing that:

Even if I don't share your worries, you're definitely not wrong for feeling the way you do. You're the mom, you make the decisions.

The agentive role mothers want to play, and their emotional reactions of anger and distrust were normalized, as in the words of this poster:

\begin{abstract}
No, you're not overacting. While it's not a matter of national security for the country, it's an extremely violating feeling.
\end{abstract}

To some extent, then, such an agentive role was also expected by posters. Such an expectation is in line with the idea that governing the child's experience with (social) media is proper of a "responsible" parent (Caronia, 2010), who in this case needs to clearly set and reinforce boundaries: "Big girl panties! Firm! Draw the lines and stick to it." Framing the "good mother" identity on parenting forum with respect to how to raise a child is not new (Pedersen, 2016). These threads, though, add to the literature the figure of the good mother who 
actively seeks to manage her child's digital footprints on social media as a new pressure on contemporary motherhood, as indicated in this poster's words:

I feel that it is my job as little guy's mom to look out for his wellbeing, and I personally feel that this include protecting his privacy and identity. When he is old enough to make social media decisions for himself, then so be it.

In terms of solutions to take, mothers provided a set of advice ranging from more dialogical and open to radical ones. We found three main courses of action mothers were advised to take, sometimes based on analogous experiences commenters had themselves: educating the MIL, controlling access to photos and information, and relational cut off.

Educating the MIL entailed opening a conversation where the DIL would explain her reasons for wanting to have control of her child's social media presence, setting boundaries upfront or remarking and clarify them if violated. Such a solution aims at safeguarding the relationship without diminishing the role of the mother. This position recurred when the MIL was framed as "trainable". In order to help mothers educate their MILs, commenters recounted personal experiences, provided them with possible statements to use to ease the process, and indicated several online supporting documents (like articles on the importance of privacy and social media rules) to back their claims. As this mother states:

There are tons of articles about "Facebook Etiquette" if you google. I'd find one that talks about how sharing pics that aren't yours is rude and send it to MIL. Maybe she'll get it if she realizes it's not a you thing, but a fairly common etiquette rule.

Controlling access to photos and information was a common solution to adopt in case educating the MIL was not effective. When MIL was seen as intentionally vio- lating boundaries, commenters suggested several actions to take. These ranged from reporting the posts (e.g. to Facebook) and have them taken down, to stop sending her information (concerning the unborn) and photos (about the born child) or block her access to the mother's social media where she could get photos and re-post them. Blocking, though, was not always perceived as wise, because it would not allow the mother to monitor the MIL's account, as this poster claims:

I wouldn't block her. That would only make it harder for OP (original poster) to see and report any inappropriate photos she uploads to Facebook from her own camera.

Another suggested solution was to "watermark" the photo to control their spreading online and hold the violators accountable. The general idea here was that the mom had to step up and set clear online boundaries, regardless of what the MIL would think about it:

\begin{abstract}
She doesn't have to realize your reasons or even understand them. She just has to follow them or face the consequence of never having any photos of your children.
\end{abstract}

Finally, the relational cut off was a desperate-times-call-for-desperate-measures kind of solution, indicated when the MIL was deemed to be "untamable" and no other actions could be effective. In these cases, according to the posters, the best move for the mother to make was to erect rigid boundaries (Minuchin, 1974) by cutting off the MIL from family life. Such a solution was adopted by several mothers who reported to have MILs blatantly ignoring and repeatedly challenging their rules. As this mother advised:

If someone is going to be so bold to TELL you that they'll do something when they know you don't want it, you should feel no guilt in cutting them off. 


\subsection{The role of the husband toward a systemic differentiation}

Whatever the solution, an overarching theme concerned the role of the husband in dealing with these predicaments. While the mother was always framed as responsible for her child, posters collectively stressed the importance of "being on the same page" with the husband when it comes to set boundaries about children's social media presence. Such an agreement was conceptualized in the "two Yes, one No rule" indicating that "both parents have to agree to something for the baby or it doesn't happen." Further, the husband was held accountable to face the predicaments with MIL and implement solutions that could restore parental agency and mark what the MIL, as member of an external system, could do or not. Depending on the way the father would deal with these situations, posters conceptualized three figures which can be positioned on a different gradient of systemic differentiation: the supportive husband, the disengaged husband, and the mom-enmeshed husband.

The supportive husband was the one who agreed with the mother in terms of online boundaries between systems, ready to set and enforce rules as needed. One of the commenters pointed the role played by her partner when, during pregnancy, she feared her MIL could post something:

My MIL is ALWAYS on FB and that made me worried she would share something. So my husband and I sat her down to discuss this before she was born.

In line with previous literature, being on the same page when it comes to face (online) boundary predicaments was related to marital satisfaction (Bryant et al., 2001). Indeed, this type of husband was described as "amazing" and "always ready to stand up to MIL", helping to draw a clear line with the MIL in case of a boundary crossing and affirming the nuclear family as a first-level system in terms of social media decisions. Mothers recognized that such a clear stance could cause tensions between the husband and his own mother and were appreciative of this gesture. One poster who had a fight with her MIL sharing pictures of her son without consent recounted how her husband was "at the forefront in putting her in her place", recognizing how difficult this could be for him but still praising his commitment:

It breaks my heart for him, but I love that he is not running to appease mommy. He has been absolutely phenomenal, and I have never been more in love with him than I am right now.

The supportive and collaborator husband, then, was framed as the one who fosters clear boundaries and neat systemic differentiation.

The disengaged husband, in turn, minimizes mother's worries and acts inconsistently with the rules she sets. As this mother who solicited her husband to tell MIL not to post about their child reports:

I have tried talking through it multiple times but he doesn't see the problem. He believes because it's her first grandchild it's normal.

Another mom had her partner make fun of her, underestimating her concerns: "He just chuckled and when I asked him why he smiled he said I'm making a big deal out of nothing." Several mothers lamented that while they tried to control MILs' posting about their children online by, for example, not providing pictures, the husbands would send them regardless because they saw nothing wrong with it. This caused feelings of frustration, not only because their perspectives were devalued, but also because this inconsistency would cause their efforts to be useless and their positions to be taken less seriously. Such behavior would send a contradictory message in terms of what the nuclear family's social media expectations were, as this poster stressed: 
You both know who she is and yet your husband continues to feed her pictures knowing she's going to share them far and wide with who even knows who. Stop doing that. It sends her a very mixed message. You're telling her to stop but you're still giving her access to what causes the problems.

Having the husband not taking the need for social media rules seriously, then, would cause a situation where boundaries between systems concerning this issue could generate confusion and enhance tensions, not only inter- but also intra-systemically. This behavior was firmly and harshly condemned by several posters, according to which the husband was being too disrespectful, as this mom claims:

You, the mother, have certain reservations regarding social media and your kids, and he's letting these people shit all over your limits and you.

Lastly, the mom-enmeshed husband was defined as a partner unable not to mark per se, but mostly to maintain clear boundaries with the MIL, because of a too intense relationship with her causing a systemic enmeshment. While these occurrences were rare, they were intense in terms of posters reactions. As an example of that, here is a suggestive case of a mom whose husband she had established clear social media rules with had "a weakness for his mother", not allowing him to reinforce these rules with MIL. While the mother didn't want him to interrupt relationships with his mom because of this, she cared about having him back her when reinforcing the social media family's expectations after the MIL violated them:

I don't expect him nor do I want him to completely cut her out from his life. I just want there to be boundaries.

This occurrence was overly problematized by other posters who suggested that the source of the dilemma was not the MIL but the husband himself. As these commenters state:

You have a dumb-husband problem not a MIL problem. Does he ignore and dismiss you, and your concerns all the time? Or just when it comes to his mommy? Are you always deprioritized?

Why is it more important for your husband to kiss his mom's ass when she DELIBERATELY broke a clearly stated parenting rule than to protect his son and stand by his wife?

Following along this problematization trajectory, mothers stressed the need for the husband to actively support his wife, considering social media dilemmas as one of the many cases where members of the nuclear family had to establish clear lines of demarcation with other systems. As exemplified by these excerpts:

\footnotetext{
Now that he has a baby he has to accelerate the timeline for separating from his parents and building adult relationships with boundaries and mutual respect.

Relationships with other people - particularly his mother - need to evolve into a new pattern.
}

\section{Conclusions}

This paper has investigated SMDs associated with sharing about children online as a source of dialectical tensions between DILs and MILs. In doing so, our findings suggest that SMDs can be an extension of other previous dialectical issues among family members, as a new possibility of boundary predicaments. Livingstone (2006) points out that in the Western culture privacy definitions concern keeping info out of the public domain or controlling which personal info is available to who, with particular anxieties surrounding children and the Internet. Questions of children's privacy and parental agency were, in fact, recurrent in our corpus of data, stressing the role of the MIL as a boundary crosser and of the 
"good" mother trying to restore her agency rights. Boundary predicaments, however, don't happen in a vacuum. While mothers' work to manage their children's online presence was almost taken for granted, an active role of the husband was expected and sometimes required to maintain relational satisfaction and to more vigorously enforce rules concerning the whole nuclear family as a higher-level system compared to other figures - in this case the MIL - from external interacting systems surrounding the child.

As posting about children on social media is a normalized practice (Leaver, 2018), managing children's digital footprints can be a complicated effort, where matters of agency and privacy intertwine: it is not only about preventing something from being shared, but being in control of that content. This is all the more true when making decisions about third parties. Indeed, when parents share about their children online, and they are too young to give their consent, this can be conceptualized as a first-level loss of agency, with respect to the subject whose photo / information is shared about. Because parents play the agentive role of making decisions for their children's online presence (Ammari et al., 2015), a second-level loss of agency occurs when people external to the nuclear family (e.g. the MIL) share about the child without parents' consent. We conceptualize this occurrence as indicative of a double loss of agency, where both the child and the parents lose control of the process (for other examples of such an occurrence see Cino \& Dalledonne Vandini, 2020).

By offering accounts of daily lives, these natural occurring data allowed us to explore how social media is so integrated in family life to the extent where new dilemmatic situations can arise from their use not only by members of the nuclear family, but also other figures who make decisions about children's digital footprints. As Pedersen and Lupton (2018) make the case for, investigating online threads on parenting forums helps researchers to focus on predicaments that posters felt a need to discuss strong enough "to initiate such a thread, in the knowledge that it may be read by thousands of other people" (p. 59).
As these threads focus on social media, we can get a sense of how their use can be a new source of parental worries, along with more "traditional" ones that have already been studied on parenting forums, such as pregnancy, diet, health, upbringing etc. (see Cappellini \& Yen, 2016; Das, 2017; Hookway et al., 2017). SMDs, though, are brand new. As such, the plethora of challenges stemming from them can disorient parents who cannot rely on their own experiences with traditional media, nor on their own parents' knowledge (Leaver, 2015). Discussing these quandaries with peers represents one of the ways parents can make sense of and overcome them, with online communication fostering the potential activation of hermeneutic circles (Gadamer, 1975) and the progressive construction of new cultural models (Holland \& Quinn, 1987). Which is to say that through the collective construction of these "mediated frameworks of reference" (Das, 2017) posters, as laypeople, are reinforcing and (de)constructing models of conduct concerning social media privacy and boundaries, sharing problems for which solutions and courses of actions are sought and discussed, and moral identities are framed (e.g. the "good" mother in a social media age). Not only can these frameworks of reference be of help for those parents who actually took part in the conversations, but also for those who lurked (i. e. read without taking part) or will read them in the future because they're facing similar dilemmas. As cultural models are realized through pattern of daily behavior and expressed through language and communication (Holland \& Quinn, 1987), this storage of daily experiences can function as a potential resource for parents to use when trying to make sense of SMDs.

As every source of data, though, this one as well comes with several limitations that need to be addressed. While analyzing online interactions occurring between users allowed us to take a close look at their meaning-making processes, background information was hard to identify, as well as the broader context of these posters. Still, given its qualitative nature, we looked at and were more concerned with particu- 
larity rather than generalizability of findings (Creswell, 2014). Future research can build on these findings and put them into context with self-report methods. Qualitative studies could help to explore more in-depth how parents deal with these and similar predicaments with other family members. As posters may reveal partial or inaccurate information about themselves or their children online, the nature of online data can pose challenges in terms of reaching a broader understanding of this phenomenon. This makes the effort to expand these findings with other qualitative approaches relevant to allow for a deeper interaction between researchers and interviewees. Facilitating rapport during indepth interviews, in fact, may foster a relationship of trust and thus truthfulness of the findings (Duncombe \& Jessop, 2012).

Quantitative analysis would provide an estimate of the breadth of this phenomenon. Also, in the realm of family communication issues, several variables could be taken into account to better understand these predicaments, such as the quality and characteristics of the relationship between MILs and DILs, the number of years of relationship, the age of the child, as well as that of parents and grandparents. In this sense, future research may want to investigate whether these experiences are more common with younger or older children, and if the age of the MILs and the parents contributes to them. As it is the case when working with natural data on online forums, we were not able to know demographics characteristics of the actors. The "generation" of the MILs, though, was reported several times by posters as something that may cause a lack of familiarity with social media privacy and "etiquette" (see the "Naïve MIL"), and possibly explain their photo-sharing behavior.

Additionally, while most of the posters in these threads reported to have children in the early childhood stage, it will be important to more accurately consider the age of the child. Research shows that when old enough to have a say in their social media presence, children lament their parents' photo-sharing habits when challenging the impression of themselves they want to leave online (Ouvrein \& Verswijvel, 2019). Future investigations, though, could expand these findings by also considering children's perspectives on grandparents and other adults posting about them on social media.

Finally, because we focused on the United States section of BabyCenter, this dataset is more likely to reflect North American perspectives and experiences, which should not be generalized to other cultures and geographical areas. According to $\mathrm{CPM}$, in fact, culture is a staple variable to consider when studying experiences of boundary turbulence (Petronio, 2002).

In spite of their limitations, our findings can inform communication, child and family studies scholars as well as practitioners concerned with more general family communication issues families can face in their everyday life. To this end, it is pivotal to keep in mind that parents may want to be the ones making decisions about whether and how to represent their children on social media. When addressing SMDs it is also important to recognize their potential disorienting nature, and that no easy solutions exist, especially when dealing with other family members. SMDs can constitute a new extension of previous family privacy predicaments, expanding the realm of potential dialectical tensions within the family. As such, new forms of communication and online sharing represents a new arena to study in the realm of family communication. Clear boundaries between systems, agreement between parents, mutual understanding and respect of these boundaries seem then to be pivotal for family relations to tackle these dilemmas and maintain systemic differentiation in the digital home.

\section{Acknowledgement}

The authors wish to formally thank research assistant Carlotta Bagnasco, student at the University of Milan-Bicocca, for helping to carefully and thoroughly code the database and providing insightful feedback throughout the data analysis process. 


\section{References}

Ammari, T., Kumar, P., Lampe, C., \& Schoenebeck, S. (2015). Managing children's online identities. In J. Boy, F. Detienne, \& J. D. Fekete (Eds.), Proceedings of the $33^{\text {rd }}$ annual ACM conference on human factors in computing systems (pp. 1895-1904). New York: Association for Computing Machinery Press.

Appleton, J., Hons, B. N., Fowler, C., Brown, N., \& Hons, M. N. (2014). Friend or foe? An exploratory study of Australian parents' use of asynchronous discussion boards in childhood obesity. Collegian, 21, 151-158.

Autenrieth, U. (2018). Family photography in a networked age: Anti-sharenting as a reaction to risk assessment and behaviour adaption. In Mascheroni G., Ponte C., \& Jorge A. (Eds.), Digital parenting: The challenges for families in the digital age (pp. 219-231). Gothenburg: Nordicom. Retrieved from https:/ / tinyurl.com/ Nordicom2018.

Bandura, A. (1989). Human agency in social cognitive theory. American Psychologist, 44(9), 1175-1784.

Bartholomew, M. K., Schoppe-Sullivan, S. J., Glassman, M., Kamp Dush, C. M., \& Sullivan, J. M. (2012). New parents' Facebook use at the transition to parenthood. Family Relations, 61(3), 455-469.

Bercelli, F. (1999). Analisi conversazionale e analisi dei frame. In Galatolo, R., Pallotti, G. (Eds.) La conversazione: Un'introduzione allo studio dell'interazione verbale (pp. 89-117). Milano: Raffaello Cortina Editore.

Brady, E., \& Guerin, S. (2010). "Not the romantic, all happy, coochy coo experience": A qualitative analysis of interactions on an Irish parenting web site. Family Relations, 59(1), 14-27.

Blum-Ross, A., \& Livingstone, S. (2016). Families and screen time: Current advice and emerging research. London: London School of Economics and Political Science. Retrieved from http://eprints.lse. ac.uk/66927/.

Blum-Ross, A., \& Livingstone, S. (2017). "Sharenting," parent blogging, and the boundaries of the digital self. Popular Communication, 15(2), 110-125.
Boss, P., \& Greenberg, J. (1984). Family boundary ambiguity: A new variable in family stress theory. Family Process, 23(4), 535-546.

Bryant, C. M., Conger, R. D., \& Meehan, J. M. (2001). The influence of in-laws on change in marital success. Journal of Marriage and Family, 63, 614-626.

Boyatzis, R. E. (1998). Transforming qualitative information: Thematic analysis and code development. Thousand Oaks, CA: Sage.

Campbell, J. L., Quincy, C., Osserman, J., \& Pedersen, O. K. (2013). Coding in-depth semistructured interviews: Problems of unitization and intercoder reliability and agreement. Sociological Methods and Research, 42(3), 294-320.

Cappellini, B., \& Yen, D. A. wan. (2016). A space of one's own: Spatial and identity liminality in an online community of mothers. Journal of Marketing Management, 32(13-14), 1260-1283.

Caronia, L. (2010). The family's governance of children's media consumption as a moral arena: Theoretical framework, methodology and first results of a study. RPDJournal of Theories and Research in Education, 5(1), 1-20.

Chalklen, C., \& Anderson, H. (2017). Mothering on Facebook: Exploring the privacy / openness paradox. Social Media + Society, 3(2) 1-10.

Child, J. T., \& Petronio, S. (2011). Unpacking the Paradoxes of privacy in CMC relationships: The challenges of blogging and relational communication on the Internet. In K. B. Wright \& L. M. Webb (Eds.), Computer-mediated communication in personal relationships (pp. 21-40). New York: Peter Lang.

Child, J. T., \& Starcher, S. C. (2016). Fuzzy Facebook privacy boundaries: Exploring mediated lurking, vague-booking, and Facebook privacy management. Computers in Human Behavior, 54, 483-490.

Cino, D., \& Dalledonne Vandini, C. (2020). "Why does a teacher feel the need to post my kid?": Parents and teachers constructing morally acceptable boundaries of children's social media presence. International Journal of Communication, 14, 1153-1172.

Cornish, F., Gillespie, A., \& Zittoun, T. (2013). Collaborative analysis of qualitative data. 
In Flick U. (Ed.), Handbook of Qualitative Data Analysis (pp. 79-93). London: Sage. Creswell, J. W. (2014). Research design: Qualitative, quantitative, and mixed methods approaches ( $4^{\text {th }}$ ed.). Los Angeles: Sage.

Damkjaer, M.S. (2018). Sharenting = good parenting? Four Parental approaches to sharenting on Facebook. In Mascheroni G., Ponte C., \& Jorge A. (Eds.), Digital parenting: The challenges for families in the digital age (pp. 209-218). Gothenburg: Nordicom. Retrieved from https://tinyurl. com/Nordicom2018.

Danielsbacka, M., Tanskanen, A. O., \& Rotkirch, A. (2017). The "kinship penalty": Parenthood and in-law conflict in contemporary Finland. Evolutionary Psychological Science, 4(1), 71-82.

Das, R. (2017). Speaking about birth: Visible and silenced narratives in online discussions of childbirth. Social Media + Society, $3(4), 1-11$.

Degroot, J. M., \& Vik, T. A. (2017). "We were not prepared to tell people yet": Confidentiality breaches and boundary turbulence on Facebook. Computers in Human Behavior, 70, 351-359.

Duck, S., Foley, M. K., \& Kirkpatrick, D. C. (2006). Relating difficulty in a triangular world. In Kirkpatrick, D.C., Duck, S. \& Foley, M.K. (Eds.), Relating difficulty: The processes of constructing and managing difficult interaction (pp. 225-232). Mahwah, NJ: Lawrence Erlbaum Associates.

Duncombe, J., \& Jessop, J. (2012). 'Doing rapport' and the ethics of 'faking friendship'. In T. Miller, M. Birch, M. Mauthner, \& J. Jessop (Eds.), Ethics in qualitative research (2nd ed.) (pp. 107-122). London: Sage.

Dworkin, J., Connell, J., \& Doty, J. (2013). A literature review of parents' online behavior. Cyberpsychology, 7(2), 1-10.

Eriksson, H., \& Salzmann-Erikson, M. (2013). Supporting a caring fatherhood in cyberspace - An analysis of communication about caring within an online forum for fathers. Scandinavian Journal of Caring Science, 27, 63-69.

Ess, C., \& the AoIR ethics working committee (2002). Ethical decision-making and internet research: Recommendations from the aoir ethics working committee. Retrieved from http://aoir.org/reports/ethics.pdf.

Eysenbach, G., \& Till, J. E. (2001). Ethical issues in qualitative research on internet communities. British Medical Journal, 323(7321), 1103-1105.

Fagan, J., \& Barnett, M. (2003). The relationship between maternal gatekeeping, paternal competence, mothers' attitude about the father role, and father involvement. Journal of Family Issues, 24, 1020-1043.

Fingerman, K. L., \& Hay, E. L. (2002). Searching under the streetlight? Age biases in the personal and family relationships literature. Personal Relationships, 9, 415-433.

Fischer, L. R. (1983). Mothers and mothers-inlaw. Journal of Marriage and the Family, $45,187-192$.

Formenti, L. (Ed.). (2012). Re-inventare la famiglia. Santarcangelo di Romagna: Maggioli Editore.

Gadamer, H. (1975). Hermeneutics and social science. Philosophy Social Criticism, 2(4), 307-316.

Goffman, E. (1974). Frame analysis: An essay on the organization of experience. Harvard University Press.

Hays, S. (1998). The cultural contradictions of motherhood. New Haven: Yale University Press.

Heidegger, M. (1996). Being and time: A translation of Sein und Zeit. Albany, NY: State University of New York Press.

Hertlein, K. M. (2012). Digital dwelling: Technology in couple and family relationships. Family Relations, 61(3), 374-387.

Hine, C. (2014). Headlice eradication as everyday engagement with science: An analysis of online parenting discussions. Public Understanding of Science, 23(5), 574-591.

Hookway, N., Elmer, S., \& Frandsen, M. (2017). Risk, morality and emotion: Social media responses to pregnant women who smoke. Health, Risk and Society, 19(5-6), 246-259.

Holland, D. \& Quinn, N. (Eds.) (1987). Cultural models in language and thought. Cambridge: Cambridge University Press.

Holloway, D., \& Green, L. (2017). Mediated memory making: The virtual family photograph album. Communications, 42(3), 351-368.

Holtz, P., Kronberger, N., \& Wagner, W. (2012). Analyzing Internet forums: A practical 
guide. Journal of Media Psychology, 24(2), 55-66.

Hudson, J. M., \& Bruckman, A. (2004). "Go away": Participant objections to being studied and the ethics of chatroom research. The Information Society, 20(2), 127-139.

Ivan, L., \& Hebblethwaite, S. (2016). Grannies on the net: Grandmothers' experiences of Facebook in family communication. Romanian Journal of Communication and Public Relations, 18(1), 11-25.

Jang, J., \& Dworkin, J. (2012). Babycenter.com: New parent behavior in an online community. The Forum for Family and Consumer Issues, 17 (2). Retrieved from https://projects.ncsu.edu/ffci/publications/2012/v17n2-2012-summer-fall/jang-dworkin.php.

Jowett, A. (2015). A case for using online discussion forums in critical psychological research. Qualitative Research in Psychology, 12(3), 287-297.

King, S. A. (1996). Researching Internet communities: Proposed ethical guidelines for the reporting of results. Information Society, 12, 119-127.

Kozinets, R. V. (2002). The field behind the screen: Using netnography for marketing research in online communities. Journal of marketing research, 39(1), 61-72.

Kumar, P., \& Schoenebeck, S. (2015). The modern day baby book: Enacting good mothering and stewarding privacy on Facebook. In D. Cosley, A. Forte, L. Ciolfi, \& D. McDonald (Eds.), Proceedings of the $18^{\text {th }}$ ACM conference on computer supported cooperative work and social computing (pp. 1302-1312). New York: Association for Computing Machinery Press.

Leaver, T. (2015). Born digital? Presence, privacy, and intimate surveillance. In J. Hartley \& W. QU (Eds.), Re-Orientation: Translingual transcultural transmedia. Studies in narrative, language, identity, and knowledge (pp. 149-160). Shangai: Fudan University Press.

Leaver, T. (2018). Co-creating birth and death on social media. In Z. Papacharissi (Ed.), A networked self: Birth, life, death (pp. 3549). London, New York: Routledge.

Livingstone, S. (2006) Children's privacy online: Experimenting with boundaries within and beyond the family. In: Kraut, R.,
Brynin, M., \& Kiesler, S., (Eds.), Computers, phones, and the internet: Domesticating information technology (pp. 145-167). New York: Oxford University Press. Livingstone, S., Blum-Ross, A., Zhang, D. (2018). What do parents think, and do, about their children's online privacy? Parenting for a digital future. London: London School of Economics and Political Science.

Livingstone, S., Stoilova, M., \& Nandagiri, R. (2018). Children's data and privacy online: Growing up in a digital age: An evidence review. London: London School of Economics and Political Science.

Lupton, D. (2013). The social worlds of the unborn. Basingstoke: Palgrave Macmillan

Lupton, D., Pedersen, S., \& Thomas, G. M. (2016). Parenting and digital media: From the early web to contemporary digital society. Sociology Compass, 10(8), 730-743.

Lupton, D., \&Williamson, B. (2017). The datafied child: The dataveillance of children and implications for their rights. New Media and Society, 19(5), 780-794.

Markham, A., \& Buchanan, E. (2012). Ethical decision-making and Internet research: Recommendations from the AoIR ethics working committee (version 2.0). Retrieved from https://aoir.org/reports/ethics2.pdf.

Marx, G. T. (1998). Ethics for the new surveillance. The Information Society, 14(3), 171-185.

Mascheroni, G. (2018a). Datafied childhoods: Contextualising datafication in everyday life. Current Sociology. Advance online publication. https://doi. org/10.1177/0011392118807534.

Mascheroni G. (2018b). Researching datafied children as data citizens. Journal of Children and Media, 12(4), 517-523.

Mezirow, J. (1991). Transformative dimensions of adult learning. San Francisco, CA: Jossey-Bass.

Miles, M.B., \& Huberman, A.M. (1994). Qualitative data analysis (2nd ed.). Thousand Oaks, CA: Sage.

Milne, A., Weijs, C. A., Haines-Saah, R. J., \& McLaren, L. (2017). Parents' online discussions about children's dental caries: A critical content analysis. Canadian Journal of Public Health, 108(3), 265-272. 
Minuchin, S. (1974). Families and family therapy. Cambridge, MA: Harvard University Press.

Morr Serewicz, M. C. (2008). Toward a triangular theory of the communication and relationships of in-laws: Theoretical proposal and social relations analysis of relational satisfaction and private disclosure in inlaw triads. Journal of Family Communication, 8(4), 264-292.

Orletti, F. (2000). La conversazione diseguale. Potere e interazione. Roma: Carocci.

Ouvrein, G., \& Verswijvel, K. (2019). Sharenting: Parental adoration or public humiliation? A focus group study on adolescents' experiences with sharenting against the background of their own impression management. Children and Youth Services Review, 99, 319-327.

Palys, T. (2008). Purposive sampling. In L. M. Given (Ed.), The Sage encyclopedia of qualitative research methods (pp. 697698). Los Angeles: Sage.

Pedersen, S. (2016). The good, the bad and the 'good enough' mother on the UK parenting forum Mumsnet. Women's Studies International Forum, 59, 32-38.

Pedersen, S., \& Lupton, D. (2018). 'What are you feeling right now?': Communities of maternal feeling on Mumsnet. Emotion, Space and Society, 26, 57-63.

Pedersen, S., \& Smithson, J. (2013). Mothers with attitude - How the Mumsnet parenting forum offers space for new forms of femininity to emerge online. Women's Studies International Forum, 38, 97-106.

Petronio, S. (2002). Boundaries of privacy: Dialectics of disclosure. New York: State University of New York Press.

Petronio, S., Jones, S., \& Morr, M. C. (2003). Family privacy dilemmas: Managing communication boundaries within family groups. In L. R. Frey (Ed.), Group communication in context: Studies of bona fide groups (pp. 23-55). Mahwah, NJ: Erlbaum.

Reid, E. (1996). Informed consent in the study of online communities: A reflection on the effect of computer-mediated social research. Information Society, 12, 169-174.

Ricoeur, P. (1970). Freud and Philosophy: An essay on interpretation. New Haven, CT: Yale University Press.
Rittenour, C. (2012). Daughter-in-law standards for mother-in-law communication: Associations with daughter-in-law perceptions of relational satisfaction and shared family identity. Journal of Family Communication, 12(2), 93-110.

Rittenour, C. E., \& Kellas, J. K. (2015). Making sense of hurtful mother-in-law messages: Applying attribution theory to the in-law triad. Communication Quarterly, 63(1), $62-80$.

Rittenour, C., \& Soliz, J. (2009). Communicative and relational dimensions of shared family identity and relational intentions in mother-in-law/daughter-in-law relationships: Developing a conceptual model for mother-in-law/daughter-in-law research. Western Journal of Communication, 73(1), 67-90.

Roberts, L. D. (2015). Ethical issues in conducting qualitative research in online communities. Qualitative Research in Psychology, 12(3), 314-325.

Saldaña, J. (2009). The coding manual for qualitative researchers. London: Sage.

Sharaievska, I., \& Stodolska, M. (2015). Redefining boundaries in families through social networking leisure. Leisure Sciences, 37(5), 431-446.

Shirani, F, Henwood, K., \& Coltart, C. (2012). Meeting the challenges of intensive parenting culture: Gender, risk management and the moral parent. Sociology, 46(1), $25-40$.

Silverstone, R. (2005) Domesticating domestication: Reflections on the life of concept. In T. Berker, M. Hartmann, Y. Punie, \& K. Ward (Eds.), Domestication of media and technologies (pp. 229-248). Maidenhead: Open University Press.

Smith, A. (2014). What people like and dislike about Facebook. Pew Research Center. Retrieved from https://www.pewresearch. org/fact-tank/2014/02/03/what-peoplelike-dislike-about-facebook/.

Smith, H., Bulbul, A., \& Jones, C. J. (2017). Can online discussion sites generate quality data for research purposes? Frontiers in Public Health, 5, 1-4. https://doi. org/10.3389/fpubh.2017.00156.

Smedley, R. M., \& Coulson, N. S. (2018). A practical guide to analysing online support forums. Qualitative Research in Psychology. 
Advance online publication. https://doi. org/10.1080/14780887.2018.1475532.

Steinberg, S. B. (2016). Sharenting: Children's privacy in the age of social media. Emory Law Journal, 66, 839-884.

Steuber, K. R., \& McLaren, R. M. (2015). Privacy Recalibration in personal relationships: Rule usage before and after an incident of privacy turbulence. Communication Quarterly, 63(3), 345-364.

Sugiura, L., Wiles, R., \& Pope, C. (2017). Ethical challenges in online research: Public / private perceptions. Research Ethics, 13(3-4), 184-199.

Sun, X., \& McMillan, C. (2018). Interplay between families and technology: Future investigations. In Van Hook, J., McHale, S.M., \& King, V. (Eds.), Families and technology (pp. 177-187). Cham: Springer.

Supple Bartels, J. (2015). Parents' growing pains on social media: Modelling authenticity. Character and ... Social Media, 1, 51-70.

Walther, J. B. (1996). Computer-mediated communication: Impersonal, interpersonal, and hyperpersonal interaction. Communication Research, 23(1), 3-43.
Walther, J. B. (2007). Selective self-presentation in computer-mediated communication: Hyperpersonal dimensions of technology, language, and cognition. Computers in Human Behaviour, 23(5), 2538-2557.

Wartella, E., \& Jennings, N. (2001). New members of the family: The digital revolution in the home. Journal of Family Communication, 1(1), 59-69.

Wartella, E., Rideout, V., Lauricella, A., \& Connell, S. (2014). Parenting in the age of digital technology: A national survey. Report of the Center on Media and Human Development. Evanston, IL: School of Communication, Northwestern University.

Webb, L. M., Ledbetter, A. M., \& Norwood, K. M. (2015). Families and technologically assisted communication. In Turner, L. H. \& West R. (Eds.), The Sage Handbook of Family Communication (pp. 354-369). Thousand Oaks: Sage.

Whiteman, N. (2012). Undoing ethics: Rethinking practice in online research. Boston, MA: Springer. 